Volume XII, No. 2, pp 264-272, 2011

\title{
ARE ALL INFORMATION SYSTEMS CREATED EQUAL - DOES ACCREDITATION SOLIDIFY INFORMATION SYSTEMS AS A DISCIPLINE?
}

\author{
Frederick G. Kohun, Robert Morris University, kohun@rmu.edu \\ Gary J. DeLorenzo, California University of PA, delorenzo@calu.edu \\ Anthony F. Rodi, California University of PA, rodi@calu.edu
}

\begin{abstract}
While there are nearly 4,000 colleges and universities that have computer/information systems (IS) related courses and programs, it can be argued that these programs have as many differences as they have similarities. Thirty three (33) of these programs are accredited by ABET-CAC. (1) In the late 1990's and early 2000's, model curricula such as the DPMA Model Curriculum, IS 97, and IS 2002 called for the development of a unified body of knowledge and basis for a consistent and recognizable information systems discipline. However, multiple factors have recently disrupted and distributed the movement towards a universally accepted common body of knowledge that is central to every discipline. This paper discusses how ABET-CAC accreditation criteria for IS programs have changed in the past ten years and that the model curriculum became more open and less distinguishable due to evolving into an outcome based model. As a result, IS programs have become less consistent and diverse to the extent its core body of knowledge has been reduced to the extent that information systems is not unified as a standalone discipline.
\end{abstract}

Keywords: ABET, Accreditation, Computer Information Systems, IS Curriculum, Information Systems

\section{INTRODUCTION}

Recently, it can be observed that IT, Security, Networking, Knowledge Management, and Cyber-Forensics-all Information Systems (IS) sub-areas - have each become more of a recognized discipline than IS. Furthermore, the ABET-CAC accreditation process, following the national trends, have focused on program outcomes, objectives and assessment as opposed to competency in a specified and universally recognized body of knowledge. Given the focus is on outcomes assessment defined and determined by the institution without rigid prescriptive guidelines, the institution/program defines its rendition of the nature of information systems education. Instead of a movement toward information system topic and content consensus, focus is in fact on assessment and meeting specific program outcomes. This trend is further complicated in a contemporary global setting by increased interest in international accreditation. The Commission on Higher Education Assessment (CHEA) is one among organizations that are attempting to provide a context for international quality standards-driven by the United States accreditation philosophy. As a result, specialized/professional accreditation while still content and discipline focused exists for many disciplines ( i.e., computer science, nursing, engineering, and education) is not indicative of information systems accreditation.

\section{BACKGROUND AND METHODOLOGY}

From an historical perspective, IS accreditation evolved from the growth of IS as a standalone discipline spun off from both business and computer science. This movement grew from the work of Gorgone, Davis, Valacich, Topi,.Feinstein, and Longenecker on the IS97 and IS2002 Model Curricula. (4) (5) This work was directed to consolidating and building consensus on what defined IS as a discipline. The accreditation criteria that emerged in 2001 reflected IS as a discipline with a specified body of knowledge associated with environmental context that included elements of computer science (i.e., programming, math, operating systems) and business. There were specified semester hour requirements, support requirement-including labs and library requirements commensurate with a standalone discipline. 
Volume XII, No. 2, pp 264-272, 2011

However, the newest ABET-CAC IS criteria focus on the national trend of outcomes assessment. The shift in assessment models has caused a greater focus on outcomes rather than on curriculum, faculty qualifications, and consistency within the discipline. (3) According to Ekstrom and Lunt, there are more significant changes coming with IS2010, in comparison with IS97 and IS2002 models. They indicate a greatly reduced emphasis on IS development and programming, while increasing emphasis on systems administration. (3)

As indicated by Bacon and Fitzgerald, the field of Information Systems faces an identity crisis and fights to gain recognition as a distinct discipline. To further complicate the identity of Information Systems, the field contains ever-changing acronyms that divides the field and makes the discipline harder to understand. (2)

Topi, et. al. states that Information Systems, as an academic field of study, exists under a variety of different names that reflect different historical developments of the discipline. It seems that the definition of Information Systems varies based on its interpretation of the discipline and how it fits into the framework of an institution. As a result, IS faculty are under pressure to develop curriculum to meet the expectations of local and regional demands as well as their own institution. IS2010 builds on the past two revisions, however, the current revision involves the effort to re-evaluate the core principles of the IS discipline through learning outcomes using four broad characteristics to shape these outcomes. The general summary of this revision includes; Reaching beyond schools of business and management towards providing expertise in an increasing number of domains; Re-evaluate outcome expectations of the curriculum in the form of high level IS capabilities broken down into three knowledge and skills categories : IS specific knowledge and skills, foundational knowledge and skills, and domain fundamentals.; Structure the curriculum so that the core curriculum is separated in order to support the concept of career tracks; Model the design of curriculum to allow flexibility in its adoption in a variety of educational system contexts. (9)

What is being compromised is the adherence to the core curriculum originally designed for the architecture of the IS discipline. These changes are moving away from the original intent of the IS discipline and drifting towards trendy program customization.

While outcomes assessment has been implicit in all accreditation venues, it has shifted to reflect the institution's mission and character. While it appears to be an enlightened approach to avoid prescriptive external standards, homogeneity of programs, a barrier to innovation—in which it has succeeded — it has reversed the universal identity and consensus as to information systems as a discipline.

\section{Criteria for Accrediting Computing Programs}

The original ABET-CAC IS criteria were used for the first time in the initial 2001 accreditation cycle. ABET-CAC IS essentially had eight categories each defined by an context statement providing the intent of the category followed by criteria that must be satisfied. These categories and criteria are detailed below. Particularly, with respect to the curriculum category, the criteria are proscribed and detailed—essentially defining a model curriculum and body of knowledge. Direct reference is made to semester hour requirements for each component of the curriculum. Furthermore, these curricular criteria reflected the body of knowledge as it stood in the IS 97 and IS2000 model curricula. (2) (3) While the ABET-CAC IS criteria did not explicitly list those model curricula, it can be argued that the curriculum criteria and model curricula were in essence mirror each other.

\section{Objectives and Assessments Category}

The first category consists of objectives and assessments. The intent of the category consists of the following statements: "The program has documented educational objectives that are consistent with the mission of the institution. The program has in place processes to regularly assess its progress against its objectives and uses the results of the assessments to identify program improvements and to modify the program’s objectives."

Criteria: To meet this intent, the following standards must be satisfied:

1. The program must have documented educational objectives.

2. The program's objectives must include expected outcomes for graduating students.

3. Mechanisms must be in place to periodically review the program and the courses.

4. The results of the program's assessment must be used to help identify and implement program improvement. 


\section{Issues in Information Systems}

Volume XII, No. 2, pp 264-272, 2011

5. The results of the program's review and the actions taken must be documented.

\section{Students Category}

The intent reads "Students can complete the program in a reasonable amount of time. Students have ample opportunity to interact with their instructors and are offered timely guidance and advice about the program's requirements and their career alternatives. Students who graduate the program meet all program requirements.”

Criteria: To meet this intent, the following standards must be satisfied:

1. Courses must be offered with sufficient frequency for students to complete the program in a timely manner.

2. Information systems programs must be structured to ensure effective interaction between teaching faculty and students.

3. Advising on program completion, course selection and career opportunities must be available to all students. 4. There must be established standards and procedures to ensure that graduates meet the requirements of the program.

\section{Faculty Category}

Faculty members' responsibility is addressed in two categories, the Faculty category, and the Program Delivery Category. The intent in the Faculty category reads "Faculty members are current and active in the discipline and have the necessary technical breadth and depth to support a modern information systems program.”

Criteria: To meet this intent, the following standards must be satisfied:

1. The interests, qualifications, and scholarly contributions of the faculty members must be sufficient to teach the courses, plan and modify the courses and curriculum, and to remain abreast of current developments in information systems.

2. All faculty members must have a level of competence that would normally be obtained through graduate work in information systems.

3. A majority of the faculty members should hold terminal degrees. Some fulltime faculty members must have a Ph.D. in information systems or a closely related area.

4. All faculty members must remain current in the discipline.

\section{Curriculum Category}

The intent of the curriculum category is "The curriculum combines professional requirements with general education requirements and electives to prepare students for a professional career in the information systems field, for further study in information systems, and for functioning in modern society. The professional requirements include coverage of basic and advanced topics in information systems as well as an emphasis on an IS environment. Curricula are consistent with widely recognized models and standards."

Criteria: To meet this intent, the following standards must be satisfied:

1. The curriculum must include at least 30 semester-hours of study in information systems topics.

2. The curriculum must contain at least 15 semester-hours of study in an information systems environment, such as business.

3. The curriculum must include at least 9 semester-hours of study in quantitative analysis as specified below under quantitative analysis.

4. The curriculum must include at least 30 semester-hours of study in general education broaden the background of the student. 5. All students must take a broad-based core of fundamental information systems material consisting of at least 12 semester hours.

6 . The core materials must provide basic coverage of the hardware and software, a modern programming language, data management, networking and telecommunications, analysis and design, and role of IS in organizations.

7. Theoretical foundations, analysis, and design must be stressed throughout the program. 
Volume XII, No. 2, pp 264-272, 2011

8. Students must be exposed to a variety of information and computing systems and must become proficient in one modern programming language.

9. All students must take at least 12 semester hours of advanced course work in information systems that provides breadth and builds on the IS core to provide depth.

10. The 15 semester hours must be a cohesive body of knowledge to prepare the student to function effectively as an IS professional in the IS environment.

11. The curriculum must include at least 9 semester-hours of quantitative analysis beyond pre-calculus.

12. Statistics must be included.

13. Calculus or discrete mathematics must be included.

14. The oral and written communications skills of the student must be developed and applied in the program.

15. There must be sufficient coverage of global, economic, social and ethical implications of computing to give students an understanding of a broad range of issues in these areas.

16. Collaborative skills must be developed and applied in the program.

\section{Technology Infrastructure Category}

The intent of this category includes "Computer resources are available, accessible, and adequately supported to enable students to complete their course work and to support faculty teaching needs

and scholarly activity.”

Criteria: To meet this intent, the following standards must be satisfied:

1. Each student must have adequate and reasonable access to the systems needed for each course.

2. Documentation for hardware and software must be readily accessible to faculty and students.

3. All faculty members must have access to adequate computing resources for class preparation and for scholarly activities.

4. There must be adequate support personnel to install and maintain computing resources.

5. Instructional assistance must be provided for the computing resources.

\section{Institutional Support and Financial Resources Category}

The institution's support for the program and the financial resources available to the program are sufficient to provide an environment in which the program can achieve its objectives. Support and

resources are sufficient to provide assurance that an accredited program will retain its strength throughout the period of accreditation.

Criteria: To meet this intent, the following standards must be satisfied:

1. Support for faculty must be sufficient to enable the program to attract and retain high-quality faculty capable of supporting the program's objectives.

2. There must be sufficient support and financial resources to allow faculty members to attend national technical meetings with sufficient frequency to maintain competence as teachers and scholars.

3. There must be support and recognition of scholarly activities.

4. There must be office support consistent with the type of program, level of scholarly activity, and needs of the faculty members.

5. Adequate time must be assigned for the administration of the program.

6. Upper levels of administration must provide the program with the resources and atmosphere to function effectively with the rest of the institution.

7. Resources must be provided to acquire and maintain laboratory facilities that meet the needs of the program.

8. Resources must be provided to support library and related information retrieval facilities that meet the needs of the program.

9. There must be evidence of continuity of institutional support and financial resource.

\section{Program Delivery Category}

The second faculty category is called Program Delivery. Its intent is "There are enough faculty members to cover the curriculum reasonably and to allow an appropriate mix of teaching and scholarly activity.” 
Volume XII, No. 2, pp 264-272, 2011

Criteria: To meet this intent, the following standards must be satisfied:

1. There must be enough full-time faculty members with primary commitment to the program to provide continuity and stability.

2. Full-time faculty members must oversee all course work.

3. Full-time faculty members must cover most of the total classroom instruction.

4. Faculty members must remain current in the discipline.

5. All full-time faculty members must have sufficient time for scholarly activities and professional development.

6. Advising duties must be a recognized part of faculty members’ workloads.

\section{Institutional Facilities Category}

The intent of this category states "Institutional facilities including the library, other electronic information retrieval systems, computer networks, classrooms, and offices are adequate to support the objectives of the program.”

Criteria: To meet this intent, the following standards must be satisfied:

1. The library that serves the information systems program must be adequately staffed with professional librarians and support personnel.

2. The library's technical collection must include up-to-date textbooks, reference works, and publications of professional and research organizations.

3. Systems for locating and obtaining electronic information must be available.

4. Classrooms must be adequately equipped for the courses taught in them.

5. Faculty offices must be adequate to enable faculty members to meet their responsibilities to students and for their professional needs. (4)

\section{Criteria For Accrediting Is Programs 2011-2012}

The ABET-CAC IS criteria used for the 2011 and 2012 accreditation cycle consist of two parts: 1.) general criteria and 2) IS program specific criteria. The general criteria are noticeably more general and less prescriptive than the original criteria established in 2001. In the spirit of the current assessment movement, each institution's IS program is at liberty to define their program in the way they choose so long as that evidence is provided that the criterion is met. It can be argued that the manner in which the criteria are written is significantly different from the 2001 criteria. The current criteria focus on the assessment on a unique and individualized program as opposed to the IS discipline driven focus of the 2001 criteria. By examining the flowing criteria, a reader would not be able to extract a solid and identifiable body of knowledge that would essentially define the IS discipline. Emphasis is on criterion 3 student outcomes where prescriptive focus is directed to the a - $\mathrm{i}$ criteria in the general criteria and in criterion $3 \mathrm{j}$ from the program criteria.

\section{General Criteria}

\section{Criterion 1. Students}

Student performance must be evaluated. Student progress must be monitored to foster success in attaining student outcomes, thereby enabling graduates to attain program educational objectives. Students must be advised regarding curriculum and career matters.

The program must have and enforce policies for accepting both new and transfer students, awarding appropriate academic credit for courses taken at other institutions, and awarding appropriate academic credit for work in lieu of courses taken at the institution. The program must have and enforce procedures to ensure and document that students who graduate meet all graduation requirements.

\section{Criterion 2. Program Educational Objectives}


Volume XII, No. 2, pp 264-272, 2011

The program must have published program educational objectives that are consistent with the mission of the institution, the needs of the program's various constituencies, and these criteria. There must be a documented and effective process, involving program constituencies, for the periodic review and revision of these program educational objectives.

\section{Criterion 3. Student Outcomes}

The program must have documented student outcomes that prepare graduates to attain the program educational objectives. There must be a documented and effective process for the periodic review and revision of these student outcomes.

The program must enable students to attain, by the time of graduation:

(a) An ability to apply knowledge of computing and mathematics appropriate to the discipline

(b) An ability to analyze a problem, and identify and define the computing requirements appropriate to its solution

(c) An ability to design, implement, and evaluate a computer-based system, process, component, or program to meet desired needs

(d) An ability to function effectively on teams to accomplish a common goal

(e) An understanding of professional, ethical, legal, security and social issues and responsibilities

(f) An ability to communicate effectively with a range of audiences

(g) An ability to analyze the local and global impact of computing on individuals, organizations, and society

(h) Recognition of the need for and an ability to engage in continuing professional development

(i) An ability to use current techniques, skills, and tools necessary for computing practice.

\section{Criterion 4. Continuous Improvement}

The program must regularly use appropriate, documented processes for assessing and evaluating the extent to which both the program educational objectives and the student outcomes are being attained. The results of these evaluations must be systematically utilized as input for the continuous improvement of the program. Other available information may also be used to assist in the continuous improvement of the program.

\section{Criterion 5. Curriculum}

The program's requirements must be consistent with its program educational objectives and designed in such a way that each of the student outcomes can be attained. The curriculum must combine technical and professional requirements with general education requirements and electives to prepare students for a professional career and further study in the computing discipline associated with the program, and for functioning in modern society. The technical and professional requirements must include at least one year of up-to-date coverage of fundamental and advanced topics in the computing discipline associated with the program. In addition, the program must include mathematics appropriate to the discipline beyond the pre-calculus level. For each course in the major required of all students, its content, expected performance criteria, and place in the overall program of study must be published.

\section{Criterion 6. Faculty}

Each faculty member teaching in the program must have expertise and educational background consistent with the contributions to the program expected from the faculty member. The competence of faculty members must be demonstrated by such factors as education, professional credentials and certifications, professional experience, ongoing professional development, contributions to the discipline, teaching effectiveness, and communication skills. Collectively, the faculty must have the breadth and depth to cover all curricular areas of the program.

The faculty serving in the program must be of sufficient number to maintain continuity, stability, oversight, student interaction, and advising. The faculty must have sufficient responsibility and 
authority to improve the program through definition and revision of program educational objectives and student outcomes as well as through the implementation of a program of study that fosters the attainment of student outcomes.

\section{Criterion 7. Facilities}

Classrooms, offices, laboratories, and associated equipment must be adequate to support attainment of the student outcomes and to provide an atmosphere conducive to learning. Modern tools, equipment, computing resources, and laboratories appropriate to the program must be available, accessible, and systematically maintained and upgraded to enable students to attain the student outcomes and to support program needs. Students must be provided appropriate guidance regarding the use of the tools, equipment, computing resources, and laboratories available to the program.

The library services and the computing and information infrastructure must be adequate to support the scholarly and professional activities of the students and faculty.

\section{Criterion 8. Institutional Support}

Institutional support and leadership must be adequate to ensure the quality and continuity of the program.

Resources including institutional services, financial support, and staff (both administrative and technical) provided to the program must be adequate to meet program needs. The resources available to the program must be sufficient to attract, retain, and provide for the continued professional development of a qualified faculty. The resources available to the program must be sufficient to acquire, maintain, and operate infrastructures, facilities and equipment appropriate for the program, and to provide an environment in which student outcomes can be attained. (7)

\section{Program Criteria For Information Systems}

\section{Student Outcomes}

The program must enable students to attain, by the time of graduation:

(j) An understanding of processes that support the delivery and management of information systems within a specific application environment. [IS]

\section{Curriculum}

Students must have course work or an equivalent educational experience that includes:

a. Information Systems: One year that must include:

1. Coverage of the fundamentals of a modern programming language, data management, networking and data communications, systems analysis and design and the role of Information Systems in organizations. [IS]

2. Advanced course work that builds on the fundamental course work to provide depth. [IS]

b. Information Systems Environment: One-half year of course work that must include varied topics that provide background in an environment in which the information systems will be applied professionally. [IS]

c. Quantitative analysis or methods including statistics. [IS]

\section{Faculty}

Some full-time faculty, including those responsible for the IS curriculum development, must hold a terminal degree in information systems. (8)

\section{CONCLUSIONS AND FUTURE RESEARCH}

Concentrations or tracks previously regarded as electives or special topics under the umbrella of information systems have taken on lives of their own. Cyber security, networking, data warehousing, knowledge management, cyber forensics have become stand-alone disciplines with identifiable and accepted bodies of knowledge. It can be 
Volume XII, No. 2, pp 264-272, 2011

further argued, that most of these boutique disciplines reflect greater consistency and consensus across the literature than does IS. In many cases, there are prestigious certifications that have evolved and, in fact, serve the same purpose as accreditation. A good example would be the National Security Agency Centers of Academic Excellence designation for information security programs.

The lack of consistency found with a business AACSB accreditation or an ABET-EAC engineering accreditation jeopardizes the credibility and functionality of IS as both a discipline and as a profession. Instead of being the root discipline of its sub specialties, the sub specialties have distanced themselves to individual distinction and prestige. With the globalization that is occurring and the desire to establish world standard, information systems as a discipline is in jeopardy. The Commission on Higher Education Accreditation (CHEA) in its attempts to disseminate the philosophy of accreditation and quality worldwide has spent much time advocating characteristics that define disciplines and professional bodies of knowledge. Given that IS programs vary so much in their design and content, there is reason to believe that IS will never achieve the same level of recognition as do other professions such as business, engineering, computer science, or nursing. This is evidenced that IS is rarely used elsewhere in the world. Instead information communication technologies (ICT), information technology (IT) , informatics, and information science are used interchangeably for information systems. The question remains to be answered: Is accreditation helping IS as a discipline or damaging its brand as a discipline?

While information technology drives our current society worldwide, IS as a discipline appears to have weakened. With the advent of outcomes based education, ABET-CAC IS accreditation criteria have seemingly moved from a recognizable body of knowledge driven discipline to one that focuses on program and institution mission. Accreditation is on assessment criteria as defined by the program not the discipline. As a result IS sub fields have become stand alone disciplines of greater cohesion and consensus than IS. As globalization progresses, IS is losing distinction and branding to other sub-disciplines and identities. It is suggested, IS is losing its place as a discipline due to accreditation changes that focus on individualized assessment plans that a standardized discipline focus body of knowledge. As part of our ongoing efforts in this area, future research will include case studies and data findings to substantiate our position on the eroding vision of IS as a discipline.

\section{REFERENCES}

1. ABET Program Accreditation. Retrieved May 7, 2011 from http://www.abet.org/AccredProgramSearch/AccreditationSearch.aspx

2. Bacon, James C., Fitzgerald, Brian (2001) “A Systematic Framework for the Field of Information Systems," The DATABASE for Advances in Information Systems, Volume 32, Number 2, Spring 2001, pp. 46-67.

3. Ekstrom, Joseph J. and Lunt, Barry M. (2010) “ Academic IT and Adjacent Disciplines 2010,”In Proceedings of the 2010 ACM SIGITE Conference on Information Technology Education (Midland, MI, USA, October 7-9, 2010). SIGITE 2010. ACM, New York, NY, pp. 1-8. http://portal.acm.org/citation.cfm?doid=1867651.1867653

4. Gorgone, John T., 2000, “Information Systems Accreditation: Revisited”, White Paper, http://cis.bentley.edu/ISA/pages/documents/acrd_sigcsecol4v4.pdf

5. Gorgone, John T., Gordon B. Davis, Joseph S. Valacich, Heikki Topi, David L.Feinstein, Herbert E. Longenecker Jr.(2002) "IS2002 Model Curriculum and Guidelines for Undergraduate Degree Programs in Information Systems”, Association for Information Systems, Atlanta, GA, http://192.245.222.212:8009/IS2002Doc/Main_Frame.htm

6. Kohun and Wood, December 27, 2003, Information Systems Education Journal "Information Systems Accreditation”, http://isedj.org/1/43/ December 27, 2003 ISEDJ

7. CRITERIA FOR ACCREDITING COMPUTING PROGRAMS, Effective for Evaluations During the 20112012 Accreditation Cycle Incorporates all changes approved by the ABET Board of Directors as of October 30, 2010, p 3-4.

8. CRITERIA FOR ACCREDITING COMPUTING PROGRAMS, Effective for Evaluations During the 20112012 Accreditation Cycle Incorporates all changes approved by the ABET Board of Directors as of October 30, 2010, p 6 
Volume XII, No. 2, pp 264-272, 2011

9. Heikki Topi, Joseph S. Valacich, Ryan T. Wright, Kate M. Kaiser, J.F. Nunamaker, Jr., Janice C. Sipior, G.J. de Vreede (2010) "IS2010 Model Curriculum and Guidelines for Undergraduate Degree Programs in Information Systems", Association for Computing Machinery, New York, NY, and Association for Information Systems, Atlanta, GA. http://www.acm.org/education/curricula/IS\%202010\%20ACM\%20final.pdf 